\title{
Peer education, gender and the development of critical consciousness: participatory HIV prevention by South African youth
}

\author{
Catherine Campbell ${ }^{\mathrm{a}, *}$, Catherine MacPhail ${ }^{\mathrm{b}}$ \\ ${ }^{a}$ Department of Social Psychology, London School of Economics and Political Science. Houghton Street, London, WC2A 2 AE, UK \\ b Miningtek, CSIR, P.O. Box 91230, Auckland Park 2006, South Africa
}

\begin{abstract}
Despite the growing popularity of participatory peer education as an HIV-prevention strategy worldwide, our understandings of the processes underlying its impact on sexual norms are still in their infancy. Starting from the assumption that gender inequalities play a key role in driving the epidemic amongst young people, we outline a framework for conceptualizing the processes underlying successful peer education. We draw on the inter-locking concepts of social identity, empowerment (with particular emphasis on Freire's account of critical consciousness) and social capital. Thereafter we provide a critical case study of a school-based peer education programme in a South African township school, drawing on a longitudinal case study of the programme, and interviews and focus groups with young people in the township. Our research highlights a number of features of the programme itself, as well as the broader context within which it was implemented, which are likely to undermine the development of the critical thinking and empowerment which we argue are key preconditions for programme success. In relation to the programme itself, these include peer educators' preference for didactic methods and biomedical frameworks, unequal gender dynamics amongst the peer educators, the highly regulated and teacher-driven nature of the school environment and negative learner attitudes to the programme. In relation to the broader context of the programme, we point to factors such as limited opportunities for communication about sex outside of the peer educational setting, poor adult role models of sexual relationships, poverty and unemployment, low levels of social capital and poor community facilities. We discuss the implications of our findings for the design of peer educational activities, and point to a number of broader social and community development initiatives that would maximize the likelihood of programme success. (C) 2002 Elsevier Science Ltd. All rights reserved.
\end{abstract}

Keywords: HIV/AIDS; Peer education; Young people; South Africa

\section{Introduction}

Drawing on Paulo Freire's notion of critical consciousness, this paper presents a critical discussion of a school-based participatory peer education programme aimed at reducing HIV transmission amongst young people in a South African township. In South Africa

*Corresponding author. Tel.: +44-20-7955-7701; fax: +4420-7955-7565.

E-mail addresses: c.campbell@1se.ac.uk (C. Campbell), cmacphai@csir.co.za (C. MacPhail). there are particularly high levels of HIV amongst young people, despite sound levels of knowledge about sexual health risks. In Summertown ${ }^{1}$, our region of interest near Johannesburg, a recent community survey found that HIV prevalence was $0.2 \%$ and $8 \%$ for men and women aged $15,11 \%$ and $47 \%$ for men and women aged 20 , and $39 \%$ and $58 \%$ for men and women aged 25, respectively (Williams, MacPhail, \& Campbell,

\footnotetext{
${ }^{1}$ The name of our area of interest has been changed, and minimal details will be given about this area, in order to disguise the identity of the school.
} 
2000a). Levels of perceived vulnerability amongst this group are low, and unprotected sex is common (MacPhail \& Campbell, 2000). In focus group research we found, unsurprisingly, that gender identity played a key role in high-risk sexual behaviour. Young peoples' sexual encounters were negotiated within a context where dominant social norms of masculinity portrayed young men as conquering heroes and macho risk-takers in the sexual arena, and where the social construction of femininity predisposed women to use the responses of passivity or fruitless resistance in the face of male advances (MacPhail \& Campbell, 2001). Within such a context, sex often took place under conditions of at best, emotional pressure, and at worst, physical coercion of young women. Our findings were consistent with a large literature that suggests that the empowerment of young women is an important precondition for safer sex amongst young people.

It is in the context of our interest in the possibility of changing gender norms as an HIV prevention strategy that this paper provides a critical case study of a participatory programme seeking to empower young people. Our programme of interest uses the method of peer education, one of the most commonly used strategies of HIV prevention worldwide (Horizons, 1999). Peer education involves the dissemination of health-related information and condoms by members of target groups to their peers. Such programmes have been shown to increase condom use and reduce levels of HIV and other sexually transmitted infections (STIs) in some countries and contexts in central and southern Africa (Vaz, Gloyd, \& Trindade, 1996; Laukamm-Josten et al., 2000; Wolf, Tawfik, \& Bond, 2000). Others have had more limited success (Leonard et al., 2000). The approach has also been effective in sexual health promotion amongst young people in certain contexts in the United States (Janz et al., 1996).

However, while peer educational approaches have increased in both popularity and practice amongst sexual health promoters, our understandings of the processes and mechanisms underlying their successes or failures are still in their infancy. As a result, our ability to learn lessons from successful and unsuccessful programmes is limited. Peer education has been described as "a method in search of a theory" (Turner \& Shepherd, 1999) and it has also been argued that peer education "suffers from an inadequately specified theoretical base" (Milburn, 1995). This dearth of theory is reflected in existing research into peer education, which tends to take the form of quantitative outcome evaluations of interventions (MacPhail \& Campbell, 1999). Such studies usually describe the extent to which programmes result in changes in target individuals' HIV-related knowledge, attitudes and reported behaviours, with little systematic discussion of the processes whereby peer education has its allegedly beneficial effects on health.

In this paper we have two goals. Firstly, we outline what we believe are the key elements for a conceptual framework for understanding peer education, in the light of the gap in understandings identified above. Central amongst these elements is Paulo Freire's account of the development of critical consciousness. Secondly, we use this conceptual framework as the basis of a discussion of a number of factors that enable and constrain the potential success of peer education programmes in the South African township context. In conclusion, we discuss the implications of our critique for the design of future peer education programmes.

\section{Theoretical framework}

In this section we will highlight the ways in which the inter-locking concepts of social identity, empowerment and critical consciousness, and social capital provide a useful starting point for theorizing the processes whereby peer education might serve as a mechanism for promoting safe sexual behaviour by youth.

\section{Social identity}

Social identity refers to "the knowledge that we belong to particular groups, together with the emotional and value significance of group membership" (Tajfel, 1981). Group memberships are associated with various "recipes for living" — group specific practices and norms (Campbell, 1995). To date, the concept of social identity has featured in two bodies of literature that are relevant to our interests in participatory health promotion. The first is that on the determinants of health-related behaviour. In contrast to views that health-related behaviours are determined by individual rational choice, the social identity literature emphasizes how healthrelated behaviours are shaped and constrained by collectively negotiated social identities (Stockdale, 1995). Thus, for example, using a condom, or visiting a traditional healer, are acts structured by social identities, rather than simply by individual decisions.

The past decade has seen a drift away from information-based health education towards participatory approaches within HIV prevention (Beeker, Guenther-Gray, \& Raj, 1998). This change in practice has gone hand in hand with a conceptual shift away from understanding 'sexual behaviour' as the product of individual decisions, in favour of a preference for the concept of 'sexuality' as a socially negotiated phenomenon, strongly influenced by group-based social identities, and more particularly peer identities. Peer group norms are seen as the result of a process of collective negotiation by young people in group settings. Ideally, 
the peer education setting should form a microcosm of "the thinking society", a term used by Billig (1996) to refer to the way in which social identities and their associated recipes for living are collectively shaped through debate and argumentation in everyday life contexts.

Traditional didactic health education seeks to change the views and attitudes of single individuals. By contrast, peer educational settings promote assimilation or accommodation of a range of individuals' opinions within an evolving group process. Individual inputs weave and clash through the process of dialogue and argument between peers, as they ask one another questions, exchange anecdotes and comment on one another's experiences and points of view. Ideally peer educational settings provide a forum where peers can weigh up the pros and cons of a range of behavioural possibilities, developing accounts of alternative behavioural norms and options in their own terminology and in the light of their own priorities (Campbell, 2000).

The second relevant 'social identity' literature that is important for understanding peer education relates to the role of identities in changing power relations. This literature is particularly relevant given the key role that gendered power relations play in shaping youth sexuality. Identity is said to play a key role in the processes whereby unequal power relations (such as relations between men and women) are reproduced or transformed. Identities are constructed and reconstructed within a range of structural and symbolic constraints that often place limits on the extent to which people are able to construct images of themselves that adequately reflect their potentialities and interests. Thus for example, female identities are often constructed in ways that predispose women to collude with men in sexual relations that do not necessarily meet their needs and interests. These include practices such as forced sex, or sexual relationships that prioritize male pleasure over female pleasure (Holland, Ramazanoglu, Sharpe, \& Thomson, 1998). Ideally, peer educational settings should provide a context within which a group of young people may come together to construct identities that challenge the ways in which traditional gender relations place their sexual health at risk (Campbell \& Jovchelovitch, 2000). In such a situation, social identities become potent tools for social change.

\section{Empowerment and critical consciousness}

The issues of gender and identity go hand in hand with the concept of empowerment. The re-negotiation of collective identities within peer education settings needs to take place in conjunction with the development of target groupings' confidence and ability to act on collective decisions in favour of health-enhancing behaviour. Much work has been done on the role of empowerment in shaping health-enhancing behaviour change (Rappaport, 1987). Such work starts with the assumption that powerlessness or a "lack of control over destiny" severely undermines the health of people in chronically marginalized or demanding situations (Wallerstein, 1992). Disempowered people, who have little control over important aspects of their lives, are less likely to feel that they can take control over their health, and are less likely to engage in health-enhancing behaviours (Bandura, 1996).

Understandings of the concept of empowerment vary. Some writers have emphasized the role that psychological empowerment plays in promoting the performance of health-enhancing behaviours. This is a fairly superficial notion of empowerment, which believes that people can be empowered at the individual level through methods such as assertiveness training courses. Others have been fiercely critical of the psychological reductionism inherent in this understanding of empowerment. Critics argue that psychological empowerment is inextricably linked to real political and economic empowerment. Unless participatory health promotion programmes are accompanied by real changes in the access that target audiences have to real symbolic power (defined in terms of perceived respect and recognition from others) and/or economic power, they are unlikely to succeed (Tawil, Verster, \& O'Reilly, 1995).

The understandings of empowerment outlined above tend to focus on the emotional or motivational dimensions of empowerment, conceptualizing it in terms of a subjective sense of confidence, in addition to the individual's objective ability or potency to act, given structural constraints. Paulo Freire's (1993a, b) conceptualization of empowerment adds a more cognitive or intellectual dimension, focusing on peoples' intellectual analyses of their circumstances. He argues that a vital precondition for positive behaviour change by marginalized social groups is the development of "critical consciousness". The Freirian notion of critical consciousness involves two key dimensions. Firstly, it refers to the development of intellectual understandings of the way in which social conditions have fostered peoples' situations of disadvantage. In terms of our interests, this would involve some kind of intellectual understanding of the way in which factors such as poverty and gender shape the poor sexual health experienced by township youth. Such intellectual understandings are an important precondition for groups to work together to develop a sense of personal and collective confidence in their ability to safeguard their sexual health. This is done through actively working to challenge or resist some of the processes whereby adverse social circumstances place their health at risk (Freire, 1993a, b).

Thus for example, a successful peer education programme might provide a group of young men with 
opportunities to discuss how the construction of masculine identity increases their risk of poor sexual health; and how poverty and unemployment limit the opportunities for the achievement of a masculine identity. Unemployed men are constrained in taking on the male breadwinner role and in setting up their own families, when they lack the money to buy houses or pay lobola (bride-price), and may compensate for this by adopting an overly macho and controlling attitude to women in sexual relationships (Campbell, 1992). From a Freirian perspective, such understandings would form the starting point from which young men could collectively work towards redefining their masculinity in ways that were less endangering of their sexual health.

According to Freire, the development of critical consciousness involves people moving through a series of stages. The first of these is 'intransitive thought', characterized by naïve rather than critical consciousness. At this stage people lack insight into the way in which their social conditions undermine their well-being, and do not see their own actions as capable of changing their conditions. The final stage is that of 'critical transitivity'. This stage is characterized by the dynamic interaction between critical thought and critical action triggered by the ability to think holistically and critically about one's condition. A critically transitive thinker is empowered to critically reflect on the conditions that shape his or her life, and to work collectively to change these conditions on the basis of such critical insight.

According to Freire, the transition from naïve to critical consciousness involves an "active, dialogical educational programme" (Freire, 1993b, p. 19), where learners are actively involved in formulating critical analyses, and generating scenarios of alternative ways of being. However, he warns that a range of obstacles stand in the way of people benefiting from such a programme. In particular, life situations characterized by exploitation and oppression lead to the development of adapted consciousness rather than critical consciousness. Adapted consciousness refers to a state where "a person accommodates to conditions imposed on them, and acquires an authoritarian and a-critical frame of mind" (Freire, 1993b, p. 23). This constitutes a situation of "democratic inexperience" within which oppressed people have a limited ability to conceive of alternatives to existing social relations, let alone the confidence to challenge such social relations.

Within a Freirian framework, we would argue that an important goal of peer education is to provide a context for the development of young peoples' critical consciousness about their sexual health. It should do so through stimulating the development of insight into the way in which gender relations, constructed within conditions of poverty, undermine the likelihood of good sexual health. It should also stimulate the development of the belief that existing norms can be changed, as well as scenarios for alternative ways of being. Finally, it should promote a context within which young people can collectively develop the belief and confidence in their power to resist dominant gender norms, in the interests of being able to assert their sexual health.

\section{Social capital}

Our third conceptual tool is that of a "health-enabling community" (Tawil et al., 1995). This term refers to a social and community context that enables or supports the renegotiation of social identities and the development of empowerment and critical consciousness. There is currently much controversy regarding how best to conceptualize such a community, with the concept of 'social capital' featuring in many debates in this area (Blaxter, 2000; Campbell, 2000). According to the social capital approach people are most likely to undergo health-enhancing behaviour change if they live in communities characterized by trust, reciprocal help and support, a positive community identity, as well as high levels of involvement in local organizations and networks (Baum, 1999). Campbell, Wood, and Kelly (1999, p. 144) argue that the most important dimension of health-enhancing social capital is "perceived citizen power", a characteristic of communities where people feel that their needs and views are respected and valued, and where they have channels to participate in making decisions in the context of the family, school and neighbourhood.

To date, there is no research on young people's access to social capital in South Africa. However, Morrow's $(1999,2001)$ research into young people's health and social capital in a deprived community in England, highlights a range of ways in which local community life undermines the development of a sense of healthenhancing "perceived citizen power" amongst young people. Her research emphasizes the way in which young people feel excluded and devalued in their local neighbourhoods. She highlights young peoples' skepticism about ineffective school councils and what they regard as their token rather than meaningful representation on community councils. She comments on the irony that while schools ostensibly have a role to play in developing young peoples' freedom of expression and capacity for decision-making, they are often structured in a formal and authoritarian way, with young people having little real input into school governance. Several themes in Morrow's research findings are echoed in our township research. As we shall see below, in many ways local community conditions undermine the development of young peoples' social capital in South Africa. Such conditions provide scant opportunities for young people to develop a sense of critical confidence in their ability to 
shape their lives, or by implication, to take control of their sexual health.

\section{Methodology}

Summertown, our area of interest, is a township not far from Johannesburg. It has a population of 150000 black African people, living in a range of housing types, with about $65 \%$ of residents living in small formal houses and 35\% in informal shacks made of corrugated iron and wooden poles. The township has benefited from some changes since the post-apartheid government, particularly an increase in the availability of formal housing. Other changes have been slower in coming. Township residents live with high rates of crime and violence, as well as high levels of unemployment as the area's major industry has suffered serious cutbacks over the past decade. Levels of unemployment are in the region of $40 \%$. Those who are employed often have unskilled and poorly paid jobs, and levels of poverty are high. Schools are under-funded, often battling with large class sizes, under-qualified teachers and disappointing rates of school completion. South Africa continues to be characterized by dramatic social inequalities. A very small minority of young township people manages to find well-paid jobs in Johannesburg. However, the vast majority of young people do not. As will be discussed below, many young people feel trapped in a community where they see few opportunities for their future advancement, and feel very hopeless about their work prospects.

This paper draws on material from a larger empirical study of HIV transmission and prevention amongst young people in Summertown. This larger study has involved in-depth interviews with 120 young people, as well as focus groups with 44 young people, half men and half women, in the 13-25 age group. Interviews and focus groups have focused on young peoples' perceptions of health, sexuality and HIV. ${ }^{2}$ The larger study has also involved eight focus group discussions with peer educators over an eight-month period (discussed further below). We draw selectively on aspects of this material that have the potential to throw light on the impact of the peer education programme on young peoples' sexual health.

Our peer education programme used the method developed by the Project Support Group at the University of Zimbabwe (Dube \& Wilson, 1996). Twenty learners volunteered to be peer educators, 10 men and 10 women. ${ }^{3}$ They were trained in participatory

\footnotetext{
${ }^{2}$ Detailed accounts of the interviews and focus groups are provided in MacPhail and Campbell $(2000,2001)$ respectively.

${ }^{3}$ The South African Department of Education uses the term 'learners' in preference to terms such as 'scholars' or 'pupils'.
}

HIV prevention methods in a mixed sex group by the clinical outreach coordinator of the NGO set up to promote sexual health in Summertown. Peer educators were given factual information about HIV and other sexually transmitted diseases (STDs). They were also trained in participatory techniques such as role-plays and the use of music. They also distribute free condoms, of which they are given an unlimited supply.

As stated above, eight focus group discussions were held with peer educators over an eight-month period. The aim of these meetings was to gather information about peer education activities, as well as the challenges that peer educators were encountering in implementing peer education activities. Throughout this period the researchers also kept in contact with the guidance teacher who coordinated the peer education group, and with the community outreach coordinator of a local health-related NGO, who maintains a close relationship with the school at all times.

Interviews and focus groups were conducted by the second author and co-interviewers who were fluent in Tswana, our informants' first language. These were tape-recorded, transcribed and translated into English, and analyzed using NUDIST (a software program for processing large qualitative data sets). In constructing our NUDIST coding frame for the analysis of our interviews and focus groups, we were guided by Pawson and Tilley's (1997) formula for the process evaluation of programmes, viz: mechanism + context $=$ outcome. We used this formula as a framework for identifying factors that might influence the success of peer education programmes in achieving the desired outcome of safer sexual behaviour amongst young people. The categories resulting from this analysis form the sub-headings of our discussion below, which focuses firstly on our mechanism of interest (the peer education programme) and secondly on the community and social contexts within which the programme was conducted.

\section{The peer education programme}

The social construction of gender undermines the likelihood of safe sex amongst young people in our township of interest. As argued above, the development of critical consciousness of the impact of gender relations on sexual health has the potential to contribute to two key processes underlying the impact of peer education. The first of these is the collective and critical renegotiation of sexual and social identities in ways which are less damaging to young peoples' sexual health. The second of these is the development of young peoples' empowerment to implement more healthenhancing ways of being. We examine a number of factors that we believe are likely to limit the development of such critical consciousness. 


\section{The highly regulated nature of the school environment}

Among young people in South Africa the majority of peer education programmes take place within a school setting. Programmes depend heavily on school-based resources and organizational structures. What is the impact of the institutional environment on the functioning of the peer education programme? In the apartheid era, South African schooling was segregated according to racial group with the largest proportion of teacher training and resources being directed towards white schools. Schools in the townships were poorly resourced and often staffed with unqualified teachers. The standard of education provided to students was determined by race, with black students receiving poor quality education that was believed to be adequate for their subsequent station in life. There was limited opportunity for black students to progress to higher education and most were expected to work in low-paid menial labour (Christie \& Collins, 1985). Particularly in township schools there was a tradition of didactic teaching and rote learning in which free discussion and argument were not encouraged among students.

Since the election of a democratic government in 1994 there have been attempts to reformulate the education curriculum in order to move away from outdated didactic methods and to make education more socially and culturally relevant to all students. At the core of this new method has been the introduction of outcomesbased education through the development of the 'Curriculum 2005' government policy documentwhich emphasizes learner participation, activity-based education, flexibility and critical thinking. However, there has been little success in the implementation of Curriculum 2005 thus far due to confusion about the methodology, lack of teacher training and limited resources in many schools. (Review Committee on Curriculum 2005, 2000). Therefore, despite governmental policy, education in many township schools remains unchanged from apartheid times. Within such a context, our peer education programme of interest has been conducted in a school in which pupils are subject to rigidly authoritarian school rules, and didactic teaching methods, which militate against any kind of autonomy or critical thinking by pupils.

\section{Teacher control of the programme}

The rationale of peer education is that peer educators take control of programme content and activities with support from a guidance teacher. The teacher's role is that of offering on-going advice and support, but in a strictly non-directive way. This is part and parcel of the approach's more general goal to empower target groups to take control of their own health promotion, in the interests of increasing peoples' levels of perceived control over their health.

Contrary to the spirit of the approach, however, within our school of interest, peer educators fell under the strict supervision and authority of the guidance teacher and the school principal. The guidance teacher has retained absolute control over the activities of the peer educators and determines the times that they engage in their educational activities, the content of their educational messages and their access to resources. One particular way in which this has been problematic for the peer educators has been in teacher's insistence that they emphasize the importance of sexual abstinence in their programme, despite the reality of high levels of sexual activity among school pupils. Another bone of contention has been peer educator access to the school's dedicated 'HIV activities room'. The guidance teacher's limiting of access to this room so that it would remain tidy for school visitors has been a source of frustration for the peer educators.

Just prior to our final meeting with the peer educators, there was concern by a range of teachers in the school that peer educators were starting to relate to adults in positions of authority in a "disrespectful" way, and the guidance teacher summarily disbanded the peer education team. Our interviews with the peer educators and the guidance teacher highlighted very different perceptions of the reasons for this disbanding. The peer educators believed that they had been unfairly dismissed because the teacher had inexplicably taken a dislike to them. The teacher on the other hand reported that the peer educators had "taken advantage" of their privileged position, and become over-confident, losing respect for the teachers, and showing inadequate care for the room the school had set aside for peer education. She said that some of the peer educators had sought to take advantage of the status accorded to peer educators in the school community, while being tardy about fulfilling their HIV prevention duties at the school. She also reported that the school headmaster had disapproved of the fact that that some of the peer educators were selected from pupils in the final year of schooling, arguing that extra-curricular activities would distract them from studying for their matriculation exams. In consultation with other teachers, the guidance teacher selected a new group of peer educators from lower grades in the school. She reports that the team now has the full support of the teachers and the head master of the school. At the time of writing, they have just completed their training and embarked on some peer-led activities in the school.

\section{Preference for didactic methods}

Both the guidance teacher who trained the peer educators, as well as the peer educators themselves, 
were enmeshed within the old-fashioned didactic approach to education, referred to above, which characterizes education within South African township schools (Christie \& Collins, 1982; Cross, 1993). Pupils were given classroom access and time to do peer education during the school day. Despite being trained in participatory peer education skills (such as dramas and role-plays), the peer educators tended to drift towards the more familiar method of 'didactic' teaching. The peer educators would stand at the front of the classroom, and peers would sit quietly in rows and then put up their hands to ask questions. Such approaches, which see the learner as a passive 'empty vessel' to be filled with knowledge emanating from an active expert teacher, are contrary to the development of the critical debate and dialogue. Such dialogue is a key mechanism underlying the development of critical consciousness, including the development of critical conceptions of alternative constructions of gender which are less damaging of young peoples' sexual health.

\section{Biomedical vs. social content of discussions.}

The content of the peer educators' lessons was framed in terms of a biomedical discourse about sexual health risks. Lessons focused on factual information about the HIV virus, how it was transmitted through the exchange of bodily fluids and so on. Question and answer sessions following the peer educators' formal lessons tended to continue in this mould. There was no focus on the social context of sexuality, or of the way in which gender relations might serve as an obstacle to condom use.

This lack of explicit guidance on the content of peer education (e.g. explicit lessons on the way in which gender relations undermine sexual health) in the design of peer education programmes points to one of the potential contradictions of participatory approaches to health promotion. In theory, participatory approaches seek to provide the context within which target audiences will generate their own indigenous critical analyses of the causes of the health threat at hand, and will reach their own self-generated solutions on the basis of such critical analyses. Peer education is supposed to be strictly non-directive, aiming to promote the empowerment of target audiences through providing them with contexts in which they can generate their own solutions to the health risk at hand, rather than through prescribing what the content of such discussions should be (Campbell \& Jovchelovitch, 2000).

However, as we shall argue below, the ability to generate such critical analyses presupposes a very different style of thinking to that which characterizes the didactic and authoritarian style of thinking used by both our guidance teacher and our peer educators of interest. This preference for a didactic style could be characterized as one of the forms of "democratic inexperience" referred to by Freire. Unless participatory approaches include explicit guidelines on the development of critical thinking, as well as explicit guidelines for the development of gender awareness, the peer education approach could simply serve to further disempower young people in two ways. Firstly, it could simply serve to reproduce the very gender relations that lead to poor sexual health in the first place. Secondly it could inadvertently reinforce young peoples' lack of power in relation to their sexual health through creating situations where they are instructed to engage in safe sexual behaviour, without giving them any insight into the social factors which make behaviour change so unlikely.

We illustrate this point with an anecdote, drawing on our observation of a peer education meeting at another high school in Summertown. Small groups of young men and women acted out a scenario involving a young woman, who didn't have any transport money. She was offered a free ride home by a male taxi driver after an evening at a youth club. Instead of taking her home he drove her to a lonely place and proposed sex. Each small group was asked to script and act out their interpretation of this situation to the larger class, followed by a plenary discussion. From our point of view as outside observers, the common denominator in the variations of the role plays presented by the different groups of pupils was that the older man wanted sex, and the younger woman did not, but that for various reasons her power to resist was very limited. However, this "critical" factor did not emerge in the pupils' discussions. These tended to focus on various strategies the young woman might have used to deter the very insistent taxi driver, such as leaping out of the taxi and running away.

As outside observers it appeared to us that in leading these discussions, the peer educators had missed an ideal opportunity for generating discussion about the way in which factors such as age, gender and lack of money had placed the young woman in this situation. However, without explicit training in (i) critical thinking skills, and (ii) in social as opposed to biomedical explanations of HIV transmission, such discussions are unlikely to arise spontaneously. In our view, peer educators lacked both the critical thinking skills, as well as the social insights, to promote critical discussions of the kind that Freire would argue form the basis of critical action.

\section{Gender dynamics amongst peer educators}

In many ways, the relationships between peer educators served as a microcosm of the very gender relations that are believed to contribute to the likelihood of unsafe sexual behaviour. Male leadership and male decision-making characterized the style of interaction in the mixed group of peer educators, with female peer educators feeling bullied if they challenged their male colleagues. Thus for example, one woman reported 
eventually resigning from the peer educator team, despite having initially been very keen to participate, because the "guys were treating the girls so badly".

In the researcher's meetings with peer educators, discussion was almost totally dominated by two of the older male members, despite the fact that the group had initially formulated a code of conduct that emphasized that everyone should have a chance to be heard. Despite the researcher's on-going attempts to facilitate opportunities for young women to talk, this occurred infrequently throughout the eight meetings of the group.

This situation points to one of the contradictions inherent in the peer education approach. On the one hand, the approach aims to be peer-led, and to function within the context of local norms and dynamics. Furthermore, the approach seeks to promote the development of indigenous analyses of the roots of the problem at hand. Suggestions for addressing the problem are supposed to be generated by members of the target audience, rather than being imposed from the outside. Our case study illustrates the problems associated with this assumption. One cannot assume that a group of young people will necessarily have the skills or insights to engage in spontaneous critical thinking. Below we will argue that given the speed at which the HIV epidemic is progressing in our area of interest (with a doubling time of less than a year), programmes need to provide more explicit "clues" and structured exercises to promote the development of factors such as gender awareness.

\section{Negative learner attitudes to the programme}

With levels of HIV infection rocketing, many South Africans have responded with high levels of denial. Within this context, while some learners beyond the peer education team have responded to the programme in a supportive and positive way, others have not. The latter group taunts the peer educators, saying that their involvement in the programme suggests that they themselves are HIV positive. While peer educators said this teasing was not enough to prevent them from conducting peer education activities, many admitted that they found in extremely difficult to remain motivated in the face of such negative attitudes.

\section{The context of the programme}

Above we have cited the claim by Tawil et al. (1995) that the successes of HIV prevention initiatives are most likely to be maximized when they are located within broader community and social contexts that are enabling and supportive of health-enhancing behaviour change. In this section we focus on three aspects of learners' beyond-school environments that we argue have the potential to undermine programme success. These include: limited opportunities for communication about sex; poor adult role models of sexual relationships; and the quality of learners' community and macro-social environments.

\section{Opportunities for communication about sex with peers and sexual partners}

Research in Europe and America has suggested that teenagers are more likely to practice safe sex if they have opportunities to communicate openly about sex, with sexual partners, peers and parents or other significant adults (Aggleton \& Campbell, 2000). If peer education is to operate at its fullest potential, issues discussed during peer education sessions need to be exported into other areas of young peoples' lives and openly discussed and debated beyond the peer education context. Our research suggests that school-based peer education programmes operate in a vacuum, with young people having few opportunities for the discussion of sex beyond school.

\section{Communication with same sex peers}

Many young people reported that they felt most comfortable discussing sex and relationships with their same-sex peers. However for boys, such discussions tended to take the form of joking comments, rather than serving as an opportunity to share information about safe sexual practices. These joking discussions entrenched peer norms of the desirability of frequent sex, taking place at the earliest possible opportunity after meeting a potential partner, with male-centered sex focusing on male pleasure. Among groups of young women, discussions about sex were primarily concerned with the social manifestations of sexual relationships rather than the mechanics of sexual intercourse per se. While some young women said that they felt free and comfortable discussing sex with their friends, others reported feeling embarrassed when their female peers discussed sex, listening to the discussions but not participating in them. Friends of the opposite sex were not encouraged and such relationships therefore did not constitute a context where young people could communicate about sex.

\section{Communication with sexual partners}

As stated above, despite high levels of HIV related knowledge, levels of perceived vulnerability were low, and unprotected sex was common. Unsurprisingly, gender identity played a key role in high-risk sexual behaviour. Our research on young peoples' first sexual encounters has found that rape or emotional pressure is common, and foreplay is minimal or non-existent (MacPhail \& Campbell, 2000). Many young women remember their first sexual encounter as painful and 
unpleasant, regretting that it had happened. Men feel pressurized by their peers to have early and frequent sex with as many partners as possible. This pressure on young men may translate into some degree of force or coercion on young women in sexual encounters (Wood \& Jewkes, 1997).

Our interviews and focus groups suggested that there was generally no communication whatsoever about sex in boy-girl relationships. Typically young men would express a desire for sex, and young women either go along with it straight away, or else refuse for a couple of days before "giving in". In order to protect their reputations, women said that it was important not to appear available for sex (e.g. by carrying condoms). When speaking about their sexual encounters, young women generally depicted sex as something that "just happened". They spoke of sexual encounters as being unexpected, and out of their control. Within such a context the opportunities for safe sex are limited. Ironically issues such as trust and love served to further undermine condom use. Raising the issue of condoms within a loving stable boy-girl relationship was seen as an indication of lack of trust of one's partner, and frequently interpreted as an insult. In short, a range of peer norms undermine the likelihood of safe sex.

\section{Communication with adults about sex}

Research in developed countries has pointed out that poor parental communication is strongly associated with poor sexual health amongst teenagers. Young people whose parents feel easy communicating about sex are more likely to use condoms and contraception (Aggleton \& Campbell, 2000). In our area of interest, open discussion of sex between adults and young people is taboo. During feedback sessions after our focus groups discussing sex and relationships many young participants thanked the researchers for providing them with a unique opportunity to discuss sexuality with an adult "without being punished". Learners stipulated that while school teachers were often the exception to this rule, their sex education tended to be biological and involve the description of sexual organs, rather than relationships or emotions.

In interviews, young people repeatedly said that to discuss sex with their parents would signify "lack of respect", and that they would never consider attempting to do this. They also said that their parents had never raised the issue of sex with them, other than mothers telling their sons to "avoid sex, because it causes pregnancy and disease" and telling their daughters rather cryptically to "stay away from boys".

Studies in other countries have reported that apart from feeling embarrassed to discuss sex with their children, parents often believe that discussion of contraception will encourage their children to become sexually active. They tend to turn a blind eye to any evidence of teenage sexuality rather than using the opportunity for frank and informative discussion (Perrino, GonzalezSoldevilla, Pantin, \& Szapocznik, 2000).

\section{Adult role models of sexual relationships}

In-depth interviews suggested that parents were often poor role models of sexual relationships. Almost half our informants' fathers were absent. Fathers who lived with their families were frequently portrayed as stern, authoritarian and unapproachable, with little interest in the daily activities of their children and wives. Informants made frequent reference to domestic violence by fathers or boyfriends against their mothers. In short, young peoples' expectations of the quality of sexual relationships were not high.

Young people had very traditional expectations of nuclear family relationships, so single mothers were seen as objects of pity, rather than admired for their independence and resilience. Many of our informants' mothers had displayed remarkable strength and resourcefulness in supporting their children and households under conditions of tremendous poverty and disruption. Young people were very positive about their mothers and the central roles they played in their lives, describing them as powerful and caring. Yet their positive experiences of single mothering did not generalize to an enhanced sense of women's agency. Being a single mother was always portrayed as second best, someone who had had to 'make do'. A woman without a permanent man was almost always spoken of as a problem.

\section{Community and macro-social environment}

Over the past decade there have been large-scale changes in South Africa with the transition from white minority to black majority government. To what extent have these changes enhanced young peoples' control over their lives and increased their potential to make choices? In this section we will highlight the way in which our interview material provided mixed evidence in this regard. On the one hand there were positive indications of political participation at the level of voting in national elections. On the other hand, interviews and focus groups pointed to many ways in which young peoples' living conditions did not provide an ideal context for the development of a sense of empowerment and agency. They suggested that young people were repeatedly exposed to situations where they themselves or family members had been prevented from acting on decisions or achieving their hopes. We speculate that such a context could contribute to a sense of disempowerment that might undermine young people's confidence in their ability to take control of their health, 
given repeated experiences of obstacles to taking control of other areas of their lives.

\section{Poverty, lack of educational opportunities and unemployment}

Levels of social inequality in South Africa are amongst the highest in the world, and our informants' lives were characterized by extremes of poverty that shadowed almost every aspect of their lives, including their hopes and aspirations for the future. Concerns about money, food and future employment were a source of almost constant anxiety for many of the young people we spoke to. Several spoke of the stress of going to bed without food, and poverty was also repeatedly cited as a source of family conflict.

In terms of educational and career advancement our informants' prospects were bleak, with a gulf between the hopes and expectations characteristic of the "new South Africa" on the one hand, and the grim reality of lack of financial opportunity and high levels of unemployment on the other hand. The majority of young people interviewed spoke of the careers that they would have liked to follow once they had completed their schooling. However, many indicated that their chosen profession would have required further education which their families could not afford. Many, especially those from single parent families, spoke of having to terminate their studies early to engage in a fruitless search for work to support themselves and younger siblings. In some cases family poverty had forced young people to leave school before they had completed their school-leaving matriculation examination, thereby effectively preventing further educational advancement and limiting their employment potential.

Work opportunities for young people in Summertown are exceptionally limited, even by South African standards. The economy of the town depends almost completely on a large industry, which is responding to profit losses by retrenching staff. Very few of our informants had managed to find work. When asked about their employment status, they responded that they "did nothing". A few had siblings who had left Summertown and found work elsewhere. Most lacked role models for shaping their future employment, however. Most of their parents had little education and were either unemployed or employed in unskilled work. Our informants had higher expectations of the job market. They hoped that they would eventually find work of a more skilled nature than their parents had done, despite their lack of success to date.

\section{Social capital}

As discussed above, it has been argued that communities that are high in social capital are most likely to provide contexts for the identity and empowerment processes involved in health-enhancing behaviour change. In our interviews we focused on three aspects of social capital: civic participation, perceived trust and helpfulness, and a positive local identity.

\section{Civic participation}

Civic participation includes factors such as voting, as well as participation in local community organizations and networks. Levels of voting are said to be an important indicator of the strength of a local community (Putnam, 1993). In this regard, our local community was a strong one. Young people were well informed about politics, and the majority who were eligible for voting had done so. They had mixed reactions to the present (post-apartheid) government. On the one hand, they referred very positively to a large-scale government housing construction programme in the area. They also mentioned the construction of new schools, the tarring of roads and the provision of government pensions. On the other hand these positive contributions were overshadowed by what people described as the governments' poor record in creating jobs, and in tackling crime. Government shortcomings were discussed sympathetically however.

In terms of participation in local community groupings, church membership was most common. Churches most commonly attended were mainstream Christian churches and traditional African Christian Churches, although there were also some Muslims and Rastafarians among the young people interviewed. Church was highlighted as important in that it taught lessons for life and could sometimes assist members with money during times of financial need. However, although there were strong ties with the church, the high prevalence of gossip among church members precluded it from being a significant source of support in times of trouble. Some young people said they might speak to their pastor about issues that were troubling them but most said that they preferred to discuss their problems with their families, most notably their mothers.

Many young men were enthusiastic sportsmen. Due to lack of money most participated in sports such as cricket and soccer that could be played on the streets with minimal equipment. For most young men enjoyment and their desire to remain physically fit motivated their involvement in sport. A smaller number of young people belonged to burial societies, political organizations and birthday present clubs (voluntary saving organizations). These groups were not seen as valuable sources of support, however, and people said they would only approach other members with problems directly related to their group membership, and not to more personal issues. 


\section{Trust and helpfulness}

Levels of trust in our community were low. Negative gossip was a constant source of trouble between both neighbours and friends. Most informants emphasized that the only people one should trust were members of ones immediate family, particularly mothers. People were mixed in their views of the helpfulness of community members. Several said that individual families were often too burdened with their own problems and their own poverty to be of much help to anyone else. However, many gave examples of help that they had received from their immediate neighbours. These included the borrowing and lending of money and household goods as well as assisting neighbours if their water or electricity was cut off due to non-payment of bills. Despite the fact that poverty was a problem for all informants there were frequent examples given of assisting poorer families with money, clothing and transportation to hospital. In many ways the neighbourhood often functioned as an extended family with people watching one another's homes and greeting one another in a friendly manner.

\section{Community problems}

The local neighbourhood was seen as having three major problems. The first of these was the poor quality of the municipally provided services in the community. Housing was also a problem. Despite the contribution the government housing campaign was making, it still had a long way to go, and many young people still lived in squatter shacks rather than formal housing. The second negative attribute of the neighbourhood was crime. They spoke of fights, gangsterism, and petty theft as common features of their community. Many young women said that they seldom went out at night due to their fear of being raped. Assaults were a particularly severe problem over weekends and holidays when people had been drinking.

The final negative attribute of the community, already referred to above, was jealousy and gossip. Although people helped one another in emergencies, it was generally acknowledged that in conditions of great privation, people didn't want to see others making a success of their lives. Those who appeared to be improving their lot often became the focus of the hostility and jealousy of friends and neighbours.

In short, interviews painted a picture of a local community struggling against poverty, crime and lack of opportunities for young people. The lucky few who did manage to succeed in improving their lot often became the victims of gossip and jealousy. Levels of trust amongst community members were low. On the other hand, there was evidence for the existence of some local community resources. Informants spoke of some level of solidarity amongst community members, who often helped one another out in times of trouble. Our community of interest was characterized by the existence of a range of formal and informal local networks, ranging from organized churches, to informal street sports groupings. Furthermore, our informants tended to speak positively about the national government. Most who were eligible to vote had done so, and spoke positively of the government's achievements in improving housing and schooling. Dissatisfaction with the governments' poor record on employment and crime was accompanied by sympathy for the difficulties of their role. In short, in many ways young peoples' accounts of life in their local community often suggested it was an unpromising context for a peer education programme seeking to promote the empowerment of young people. There was, however, some positive evidence for a degree of political interest and informal civic participation. Below we will argue that these forms of community engagement bode positively for those seeking to promote the further mobilization of young people around their sexual health in our community of interest.

\section{Conclusion}

In this paper we have sought to highlight factors which might impact on our peer education programme's achievement of increased condom use by young people. We have done so through focusing on the programme itself, as well as relevant contextual dimensions of young peoples' lives. The paper rests on the starting assumption that gender relations constitute a key obstacle to condom use by young township people. We locate our discussion within a conceptual framework that emphasizes the role of the development of critical consciousness in the identity and empowerment processes that underlie successful peer education programmes.

Ideally peer education should provide opportunities for young people to develop a critical consciousness of the way in which socially constructed norms of masculinity and femininity place their sexual health at risk, as well as a belief in the possibility of alternative gender relations. In our view, such consciousness forms the starting point for the collective renegotiation of young peoples' social and sexual identities, and for the empowerment of young people to change their behaviour in line with such renegotiated identities.

What are the implications of our findings for HIV prevention amongst school learners? We draw on Williams and Campbell's (1998) multi-level approach to HIV prevention to elaborate. They argue that the fight against HIV in South Africa needs to involve an integration of approaches and activities over the long term (e.g. macro-economic development), medium term (e.g. working to change norms of sexual behaviour) and the short term (e.g. the aggressive detection and 
treatment of STDs). Efforts to promote the treatment of STDs are already in place in our community of interest (Williams et al., 2000b), so action has already been taken at the short-term level.

Our research points towards the need for HIV prevention workers to give their support to a number of long-term activities. These include efforts to reduce the high levels of poverty and unemployment that undermine young peoples' confidence in their ability to direct their lives and take control of their health in ways that are consistent with their hopes and aspirations. If peer education programmes are to achieve more than superficial empowerment of their participants, there is also an urgent need for the development of channels through which young people can add their voices to a variety of local and national debates. Such debates would include those about educational and social development policies and initiatives that promote contexts that support and enable improved sexual health. These would include, amongst other things, input into debates about poverty reduction programmes.

However, the struggle against poverty in southern Africa has a long history, and success in this enterprise is by no means assured within the next few years. Within such a context, to advocate economic development alone as a means of addressing an epidemic which has a doubling time of less than a year offers cold comfort. In the medium term, however, our research points to a range of interventions which could be implemented even within the context of the crippling poverty characterizing the lives of the young people in our township of interest. Many such interventions are already in the planning stages as the post-apartheid government battles to undo many of the negative legacies of the apartheid regime, characterized as it was by so many institutionalized measures designed to disempower young black South Africans. Many medium term strategies are consistent with measures already being pursued by policy makers in the educational sectors for example. In this regard, HIV activists should throw their weight behind on-going attempts to develop educational policies that encourage the development of young peoples' autonomy, and the capacity for critical thinking, which we argue is an important precondition for the renegotiation of youth norms governing sexuality and gender. Above we have referred to the government's "Curriculum 2005" education strategy that - through its 'Life Orientation Learning Area'forms a starting point for increasing young people's agency in general, and in regard to their sexual health in particular.

More specifically, much work remains to be done in developing school contexts that enable young people to exercise real leadership of HIV-prevention programmes, and real 'ownership' of the problem of rocketing HIV levels amongst youth. A constituency that assumes a sense of psychological ownership of a problem is far more likely to take measures to begin to address it.

Such within-school programmes could work hand in hand with social development programmes that seek to promote young peoples' social capital. We have referred to positive evidence for political interest and local civic participation amongst young people, as well as their sympathy and support for the government. Within the context of such interest and respect, the South African government's well-publicized ambivalence about the causes or even the existence of HIV and/or AIDS continues to be cause for concern. Our research findings point to the urgent need for the government to develop a united position on HIV/AIDS, and exercise strong leadership in this area. This is particularly important given the high levels of sympathy and respect which young people in our area of interest hold for the government.

Turning from the national to the local political scene, there is much scope for working towards increasing young peoples' opportunities to become involved in local community organizations, and in community decision making, given the role of "perceived citizen power" in increasing the likelihood of health-enhancing behaviour change.

Our research also highlights an urgent need for local community groupings to work towards raising parental levels of awareness of the importance of open and frank communication about sex, and to start developing support for parents in this task. During the course of our research, both teachers and learners repeatedly expressed the need for the development of a programme of evening meetings designed to support and enlighten parents in relation to the issues of youth sexuality. This is an area that is ripe for further development.

Moving from contextual factors to the design of peer education programmes themselves, it is vital that HIV prevention workers, peer educator trainers, peer educators and their target audiences understand the philosophy of peer education. This includes not only the importance of creating community contexts that enable and support the behaviour change that peer education seeks to promote, but also understandings of the principles underlying the need for, and the development of, critical consciousness. In relation to our particular interest in youth sexuality, peer education programmes need to contain very explicit and focused materials promoting discussions of the impact of gender relations on sexual health, for example. In the absence of such explicit conceptual underpinnings and materials, peer educational approaches are unlikely to have any 'added value' over traditional health education, with its welldocumented shortcomings (Gillies, 1998).

Paulo Freire provides many of the intellectual tools necessary to inform conceptually sound peer education 
programmes. Our empirical findings suggest it is not enough to conceptualize 'empowerment' in terms of boosting young peoples' emotional or motivational confidence in their ability to protect their sexual health. Empowerment also involves the development of intellectual understandings of the way in which social relations contribute to the transmission of HIV, and undermine efforts to reduce HIV transmission.

Our on-going research with young people in Summertown has repeatedly highlighted an awareness of gender as the key ingredient of the critical consciousness that we believe is most likely to encourage behaviour change. In our view, peer educational approaches have the greatest chance of success if they provide a context in which young people can develop insights into the way in which gender relations undermine their sexual health; promote a belief that existing norms could be different; and only then, within this context, encourage young women and men to collectively develop the belief and confidence in their power to resist dominant gender norms, in the interest of promoting their sexual health.

In our view, such an enterprise would not take place in a vacuum. The post-apartheid constitution emphasizes the equality of all South Africans, specifically prohibiting any form of discrimination or disadvantage on the grounds of gender. While there is a wide gap between ideals and their implementation, the legal institutional framework does exist for the challenge of working towards the evaluation and re-negotiation of gender norms that we believe could make such a key contribution to sexual health. As discussed above, a significant number of township women are supporting families single-handed, both economically and emotionally. Within the constraints of very severe poverty, and against the historical backdrop of strongly patriarchal social norms, women are asserting leadership in all sorts of unrecognized ways. While we have highlighted the lag between this reality, and adequate recognition of the extent of women's achievements, this situation serves as a potential point for an increased recognition of women's ability to function independently of male control and support.

In this paper, we have spoken very generally about the types of gender norms that govern the majority of young people in our research sample. This is not to say that there were no examples of counter-normative behaviour. Elsewhere we have discussed instances of young people in our study that resisted or challenged the stereotypical gender norms outlined above (MacPhail \& Campbell, 2001). Our interviews and focus groups did include a small number of very religious young men who had resisted masculine norms, deciding not to have sex before marriage. They also included a few examples of young women taking control of their sexuality, through condom use and HIV testing, with the cooperation of their boyfriends. While these counter-examples constituted a very small minority, they did exist. In the same paper, we also point to evidence that some young people were self-consciously critical of the norms that governed their sexual behaviour, despite going along with them. These young people exhibited a degree of awareness of the way in which peer and gender pressures placed their health at risk. Such young people could provide valuable input into skillfully designed peer education discussions of alternative gendered ways of being.

In this paper we hope to have contributed to a number of areas of enquiry. The first of these is the development of theoretical underpinnings for the design and evaluation of peer education programmes. We have sought to do this in the light of our more general interest in contributing to the development of a "social psychology of participation" (Campbell \& Jovchelovitch, 2000), with particular emphasis on the relevance of the work of Paulo Freire (1993a, b) to this enterprise. Secondly we hope to have contributed to understandings of the way in which community and social contexts may impact on the best-intentioned attempts to promote sexual behaviour change amongst young people. Thirdly we hope to have thrown light on the possibilities and limitations of implementing peer education within school settings, with particular reference to schools in South African township contexts. Finally, we hope to have illustrated the importance of conceptualizing school-based programmes as part of wider multisectoral responses to HIV prevention, where health activitists need to work hand in hand with those in education and social development departments, amongst others. In our view, much room exists for an acceleration of school-based responses to HIV prevention as a key dimension of the fight against HIV amongst young people.

\section{Acknowledgements}

The intervention project in which this research is located was initiated and developed by Brian Williams. Our thanks to him for support throughout the research process, and for commenting on the work that appears in this paper. Thanks also to Zodwa Mzaidume for discussion of various points. The research in this paper was funded through the UK Department for International Development, and UN AIDS. Our thanks for their financial assistance. The views expressed in this paper are those of the authors, however, and do not necessarily represent those of the funding agencies. Special thanks to the young people and education staff of Summertown for allowing us to evaluate their HIV prevention efforts and for giving us their time for interviews and focus group discussions. 


\section{References}

Aggleton, P., \& Campbell, C. (2000). Working with young people: Towards an agenda for sexual health. Sex and Relationship Therapy, 15(3), 283-296.

Bandura, A. (1996). Self-efficacy in changing societies. Cambridge: Cambridge University Press.

Baum, F. (1999). The role of social capital in health promotion: Australian perspectives. Health Promotion Journal of Australia, 9(3), 171-178.

Beeker, C., Guenther-Gray, C., \& Raj, A. (1998). Community empowerment paradigm and the primary prevention of HIV/AIDS. Social Science and Medicine, 46(7), 831-842.

Billig, M. (1996). Arguing and thinking. Cambridge: Cambridge University Press.

Blaxter, M. (2000). Medical sociology at the start of the new millennium. Social Science and Medicine, 51(8), 1139-1142.

Campbell, C. (1992). Learning to kill? The family, masculinity and the political violence in Natal. Journal of Southern African Studies, 18(3), 614-628.

Campbell, C. (1995). The social identity of township youth (Parts 1 and 2). South African Journal of Psychology, 25(3), 150-167.

Campbell, C. (2000). Social capital and health: Contextualising health promotion within local community networks. In S. Baron, J. Field, \& T. Schuller (Eds.), Social capital: Critical perspectives (pp. 182-196). Oxford: Oxford University Press.

Campbell, C., \& Jovchelovitch, S. (2000). Health, community and development: Towards a social psychology of participation. Journal of Applied and Community Social Psychology, 10, 255-270.

Campbell, C., Wood, R., \& Kelly, M. (1999). Social capital and health. London: Health Education Authority.

Christie, P., \& Collins, C. (1985). Bantu education: Apartheid ideology or labour reproduction. Comparative Education, 18(1), 59-75.

Cross, M. (1993). Youths, culture and politics in South African education: The past, present, and future. Youth and Society, 24(4), 377-398.

Dube, N., \& Wilson, D. (1996). Peer education programs among HIV-vulnerable communities in Southern Africa. In B. Williams, \& C. Campbell (Eds.), HIV/AIDS management in Southern Africa: Priorities for the mining industry (pp. 107-110). Johannesburg: Epidemiology Research Unit.

Freire, P. (1993a). The pedagogy of the oppressed. London: Penguin.

Freire, P. (1993b). Education for critical consciousness. New York: Continuum.

Gillies, P. (1998). Effectiveness of alliances and partnerships for health promotion. Health Promotion International, 13(2), 122.

Holland, J., Ramazanoglu, C., Sharpe, S., \& Thomson, R. (1998). The male in the head: heterosexuality and power. London: Tufnell Press.

Horizons. (1999). Peer Education and HIV/AIDS: Past Experience, Future Directions. Kingston: Discussion document developed by Horizons, Population Council, the Jamaican Ministry of Health, PATH, AIDSMark/PSI, IMPACT/FHI and UNAID.

Janz, N. K., Zimmerman, M. A., Wren, P. A., Israel, B. A., Freudenberg, N., \& Carter, R. J. (1996). Evaluation of 37
AIDS prevention projects: Successful approaches and barriers to program effectiveness. Health Education Quarterly, 23(1), 80-97.

Laukamm-Josten, U., Mwizarubi, B. K., Outwater, A., Mwaijonga, C. L., Valadez, J. J., Nyamwaya, D., Swai, R., Saidel, T., \& Nyamuryekung'e, K. (2000). Preventing HIV infection through peer education and condom promotion among truck drivers and their sexual partners in Tanzania. AIDS Care, 12(1), 27-40.

Leonard, L., Ndiaye, I., Kapadia, A., Eisen, G., Diop, O., Mboup, S., \& Kanki, P. (2000). HIV prevention among male clients of female sex workers in Kaolack, Senegal: Results of a peer education program. AIDS Education and Prevention, 12(1), 21-37.

MacPhail, C., \& Campbell, C. (1999). Evaluating HIV/STD interventions in developing countries: Do current indicators do justice to advances in intervention approaches? South African Journal of Psychology, 29(4), 149-165.

MacPhail, C., \& Campbell, C. (2000). Factors influencing youth HIV transmission in a South African township. Johannesburg: Unpublished report prepared for UNAIDS.

MacPhail, C., \& Campbell, C. (2001). 'I think condoms are good but, aai, I hate those things': Condom use among adolescents and young people in a Southern African township. Social Science and Medicine, 52(11), 1613-1627.

Milburn, K. (1995). A critical review of peer education with young people with special reference to sexual health. Health Education Research, 10(4), 407-410.

Morrow, V. (1999). Conceptualizing social capital in relation to the health and well-being of children and young people: A critical review. Sociological Review, 47(4), 744-765.

Morrow, V. (2001). Networks and neighborhoods: Children's and young people's perspectives. London: Health Development Agency.

Pawson, R., \& Tilley, N. (1997). Realistic evaluation. London: Sage.

Perrino, T., Gonzalez-Soldevilla, A., Pantin, H., \& Szapocznik, J. (2000). The role of families in adolescent HIV prevention: A review. Clinical Child and Family Psychological Review, 3(2), 81-96.

Putnam, R. (1993). Making democracy work. New Jersey: Princeton University Press.

Rappaport, J. (1987). Terms of empowerment/ exemplars of prevention: Toward a theory for community psychology. American Journal of Community Psychology, 15, 121-148.

Review Committee on Curriculum 2005. (2000). A South African Curriculum for the Twenty first Century. Pretoria: Report of the Review Committee on Curriculum 2005 to Minister of Education, Kadar Asmal, 31 May 2000.

Stockdale, J. (1995). The self and media messages: match or mismatch? In I. Markova, \& R. Farr (Eds.), Representations of health, illness and handicap (pp. 31-48). London: Harwood.

Tajfel, H. (1981). Human groups and social categories. Cambridge: Cambridge University Press.

Tawil, O., Verster, A., \& O'Reilly, K. (1995). Enabling approaches for HIV/AIDS promotion: Can we modify the environment and minimize the risk? AIDS, 9, 1299-1306.

Turner, G., \& Shepherd, G. (1999). A method in search of a theory: Peer education and health promotion. Health Education Research, 14(2), 235-247. 
Vaz, R. G., Gloyd, S., \& Trindade, R. (1996). The effects of peer education on STD and AIDS knowledge among prisoners in Mozambique. International Journal of STDs and AIDS, 7(1), 51-54.

Wallerstein, N. (1992). Powerlessness, empowerment and health: Implications for health promotion. American Journal of Health Promotion, 6(3), 197-205.

Williams, B., \& Campbell, C. (1998). How to control the AIDS epidemic. Focus, 10, 12-13.

Williams, B., MacPhail, C., \& Campbell, C. (in press). Relative risk of HIV infection amongst young men and women in a South African township. International Journal of STDs and AIDS.
Williams, B., MacPhail, C., Campbell, C., Moema, S., Mzaidume, Y., \& Rasego, B. (2000b). The Summertown Project: Limiting transmission of HIV through community participation. South African Journal of Science, 96(6), 351-359.

Wolf, R. C., Tawfik, L. A., \& Bond, K. C. (2000). Peer promotion and social networks in Ghana: Methods for monitoring and evaluating AIDS prevention and reproductive health programs among adolescents and young adults. Journal of Health Communication, 5(Suppl), 61-80.

Wood, K., \& Jewkes, R. (1997). Violence, rape and sexual coercion: Everyday love in a South African township. Gender and Development, 5(2), 41-46. 